\title{
MEASUREMENT OF THE HISSING-TYPE NOISE AND VIBRATION OF THE AUTOMOTIVE HVAC SYSTEM
}

\author{
Muhammad Abdul Rahman Paiman ${ }^{1,2}$, Ahmad Zhafran Ahmad Mazlan ${ }^{1 *}$ \\ Muhammad Hidayat Hamdan', Mohamad Syazwan Md. Isa', Sharum Man², \\ Mohd Zukhairi Abd. Ghapar ${ }^{2}$, Mohamad Shamsul Azraf Sulaiman² and \\ Tomoyuki Miyashita ${ }^{3}$
}

\author{
${ }^{1}$ School of Mechanical Engineering, Engineering Campus, Universiti Sains Malaysia, \\ Penang \\ ${ }^{2}$ Vehicle Comfort, Testing \& Development, Vehicle Development \& Engineering, \\ Proton Holdings Berhad, Selangor \\ ${ }^{3}$ School of Creative Science and Engineering, Waseda University. \\ *Email: zhafran@usm.my
}

\begin{abstract}
Noises such as hissing, humming, air-rush and compressor engagement are the common type of noises that can be induced from the automotive heating and ventilating air conditional (HVAC) system. These noises are basically generated from the effects of vibrational HVAC components. Due to this, the root cause of the noises has to be investigated for any implementation of solution. In this study, the hissing-type of noise is taken into consideration whereby the noise and vibration are measured from various HVAC components such as Evaporator Inlet and Outlet and Thermal Expansion Valve (TXV). Three types of measurement sensors are used in this study which is tri-axial accelerometer for the vibration, tachometer for the engine rpm tracking and microphone for the noise measurement. Two types of operating conditions are taken into consideration, when engine running at $850 \mathrm{rpm}$ (idle) and 850-3000 rpm (tracking) conditions and a constant blower speed is applied for both conditions. The result shows that, the hissing type of noise is determined at the frequency range of $4500-5000 \mathrm{~Hz}$ for the both idle and running conditions, whereby the vibration at the Evaporator Inlet is the most significant compared to the Evaporator Core and TVX components. The vibration of the Evaporator Inlet shows the drastic vibration increment between 1000-1500 rpm and getting worse towards $3000 \mathrm{rpm}$. This result is validated with the 3D colour of noise waterfall analysis, whereby the hissing noise shows the dominant result in the frequency range of 4500-5000 Hz.
\end{abstract}

Keywords: Hissing noise, HVAC system, vibration, rpm tracking and Evaporator Inlet.

\section{INTRODUCTION}

Noise and vibration of the heating and ventilating air conditional (HVAC) system is the common problem for most of the automotive manufacturers. There is a lot of noise and vibration types that can be produced from the HVAC system to the vehicle such as humming, hissing, clicking, air-rush and many more. These noises can contribute to the significant issue for driving comfort. The automotive air conditional system has several assembly parts such as compressor, condenser, radiator fan, drier, thermal expansion valve (TXV), evaporator and blower, as shown in Figure 1 
(Autointehbox, 2015). All these parts can contribute to the specific noise and vibration problem for the vehicle.

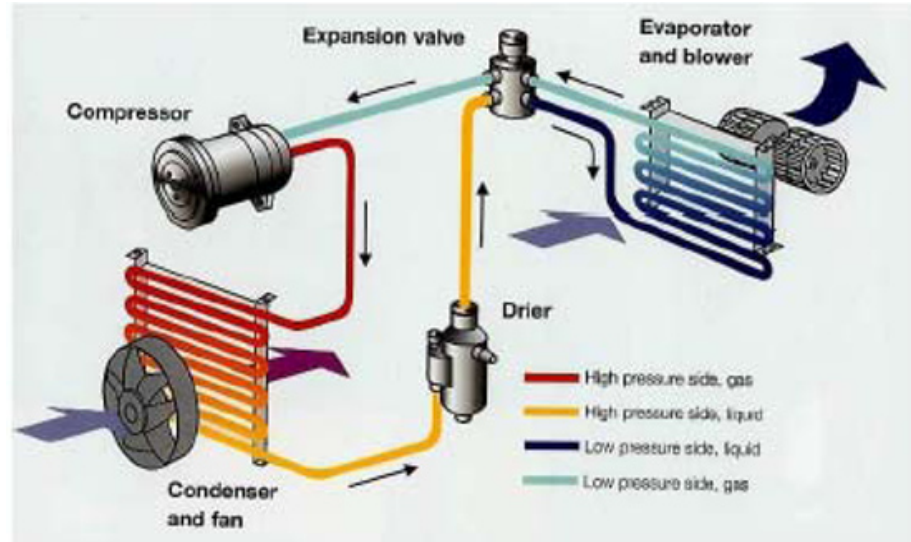

Figure 1. Common vehicle HVAC system (Autointehbox, 2015)

The current design of the HVAC system is based on the circulation of liquid refrigerant and water to perform the function of cooling and heating for the vehicle. There are two main sections of the HVAC system, one side dealing with the liquid such as condenser, drier and TXV while another side dealing with the air such as compressor, evaporator and blower. Most of the liquid side of the system is located within the engine location of the vehicle, with only two liquid-to-air heat exchangers positioned in the air handling unit inside the vehicle cabin. Both liquid and air sides can produce noise and vibration problem from various components (Kamiyama and Uomoto, 1997). One of the major HVAC components that contributed to the noise and vibration problem is a compressor. Since compressor is the main component that turned the low-pressure air to the high-pressure air, there is a high possibility in creating the noise such as humming and clicking noises. These noises are created during the compressor engagement and disengagement period of the overall HVAC system. This is the most common noise problem to the HVAC system which can damage the compressor part if no necessary action been taken (Mazlan, et al., 2018).

In order to determine the root cause and type of noise and vibration of the HVAC system, a proper set-up and methodology must be carried out. The study done by (Mavuri, et al., 2008) shows the proper methodology in measuring the vehicle HVAC cabin noise such as the testing parameters involved, instrumentation to be used and the set-up procedure. In other study, the lab scale rig has been set-up to determine the noise created from the air handling unit of the HVAC system. Based on results of this study, it was proven that by increasing the fan will increase the total noise level and magnitude of the predominant noise spectral peaks. Another finding from the study is regarding the cover of motor vent passage hole and the seal of weld gap which do not change the total noise level but do reduce the noise spectral peaks at the blade passing frequencies which also affected the cavity resonance peaks at the low frequencies (Wang and Watkins, 2007).

Since there are varies type of noise and vibration that can be induced from the HVAC components, this study only focused on one type of noise which is hissing-type noise that generated from one of vehicle HVAC components. The study consists of invehicle vibration and noise measurements at related HVAC components such as Evaporator Inlet, Evaporator Core and TXV components in order to determine the root cause of the hissing-type noise and vibration. 


\section{METHODOLOGY}

\section{Experimental Set-up}

In this section, the experimental setup for the in-vehicle hissing type noise and vibration measurement are discussed. The detail of the test flow chart and test locations of the vehicle HVAC system for the vibration and noise measurement is shown in Figure 2 (a) and (b), respectively. In Figure 2 (a), there are three typed of sensors that been used which is accelerometer for the vibration (i.e., acceleration) measurement, microphone for the noise measurement and tachometer for the rpm measurement. The signal from these sensors are recorded using the DAQ (LMS SCADAS hardware) and then the data is analyze using LMS Test.Lab software to generate the vibration, noise and rpm related figures. The detail analysis using Sound Diagnosis workbench is performed with the frequency filtering function to extract the actual hissing-type noise and vibration characteristics. The locations of measured HVAC components for the vibration and noise are shown in Figure 2(b), where there are total of three locations for the HVAC system components such as Evaporator Inlet, Evaporator Core and TXV components. These locations are the main target of the vibration induced noise for the hissing-type noise of the vehicle HVAC system.
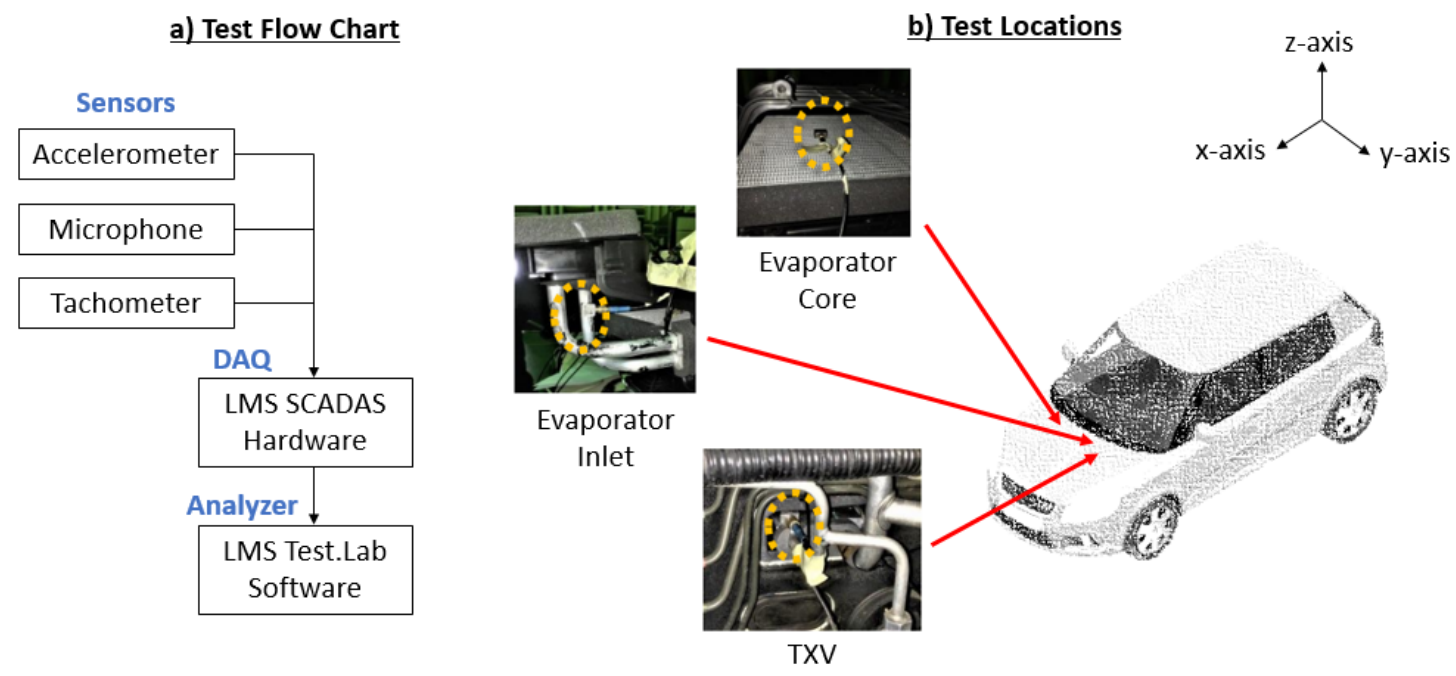

Figure 2. (a) Test flow chart and (b) Test locations of the vehicle HVAC system

\section{Testing Conditions for Hissing-type Vibration and Noise Measurement}

In order to determine the root cause of the hissing-type noise and vibration of the HVAC system, the testing conditions have to be properly decided. Table 1 shows the testing conditions for the vibration, noise and rpm tracking measurement (hissingtype) for the vehicle HVAC system. From the table, there are two test conditions applied, which is in idle (Engine speed at $850 \mathrm{rpm}$ ) and in-rpm tracking (Engine speed increasing from 850 to $300 \mathrm{rpm}$ ). For both conditions, engine status of "On", air conditional of "On" and blower speed of 1 are applied. Since this is a fundamental investigation to determine the root cause of the hissing-type noise, only one level of blower speed (i.e. 1/4 speed) is considered. Further investigation for varies blower speed setting can be performed after determining the root cause of the noise. 
Table 1. Testing conditions of the HVAC system (Hissing type).

\begin{tabular}{|c|c|c|c|c|c|}
\hline $\begin{array}{l}\text { Type of } \\
\text { noise }\end{array}$ & Test conditions & $\begin{array}{l}\text { Engine } \\
\text { status }\end{array}$ & $\begin{array}{c}\text { Air } \\
\text { conditional } \\
\text { status }\end{array}$ & $\begin{array}{c}\text { Blower } \\
\text { speed }\end{array}$ & Locations \\
\hline \multirow[b]{2}{*}{ Hissing } & Idle (850 rpm) & On & On & 1 & \multirow{2}{*}{$\begin{array}{c}\text { - Evaporator } \\
\text { Inlet } \\
\text { - Evaporator } \\
\text { Core } \\
\text { - TXV }\end{array}$} \\
\hline & $\begin{array}{l}\text { Rpm tracking } \\
\text { (850-3000 rpm) }\end{array}$ & On & On & 1 & \\
\hline
\end{tabular}

\section{RESULTS AND DISCUSSION}

\section{Hissing-type Noise and Vibration Analyses}

In this section, the result of hissing-type noise and vibration in terms of sound pressure level (SPL) and vibration amplitudes are presented using frequency domain and 3D color waterfall analysis methods. Figure 3 shows the vibration amplitude (i.e., acceleration) against rpm tracking of the Evaporator Inlet component. As shown in the figure, the acceleration of the Evaporator Inlet is low at $1 \mathrm{~m} / \mathrm{s}^{2}$ during the idle condition of $850 \mathrm{rpm}$. When the engine is started to ramp from $850-3000 \mathrm{rpm}$, the vibration amplitude of vibration increases drastically from 1000 - $1500 \mathrm{rpm}$ of range with the maximum amplitude of $1.8 \mathrm{~m} / \mathrm{s}^{2}$. After $1500 \mathrm{rpm}$, the vibration signal started to be fluctuated and getting worse for the range of $1500-2500 \mathrm{rpm}$ as shown in Figure 3. From this result, the hissing-type noise is clearly heard from the subjective feeling during this range of rpm. By referred to the subjective feeling and vibrational response in Figure 3, the result is further analyzed using the frequency domain and 3D color waterfall analysis methods.

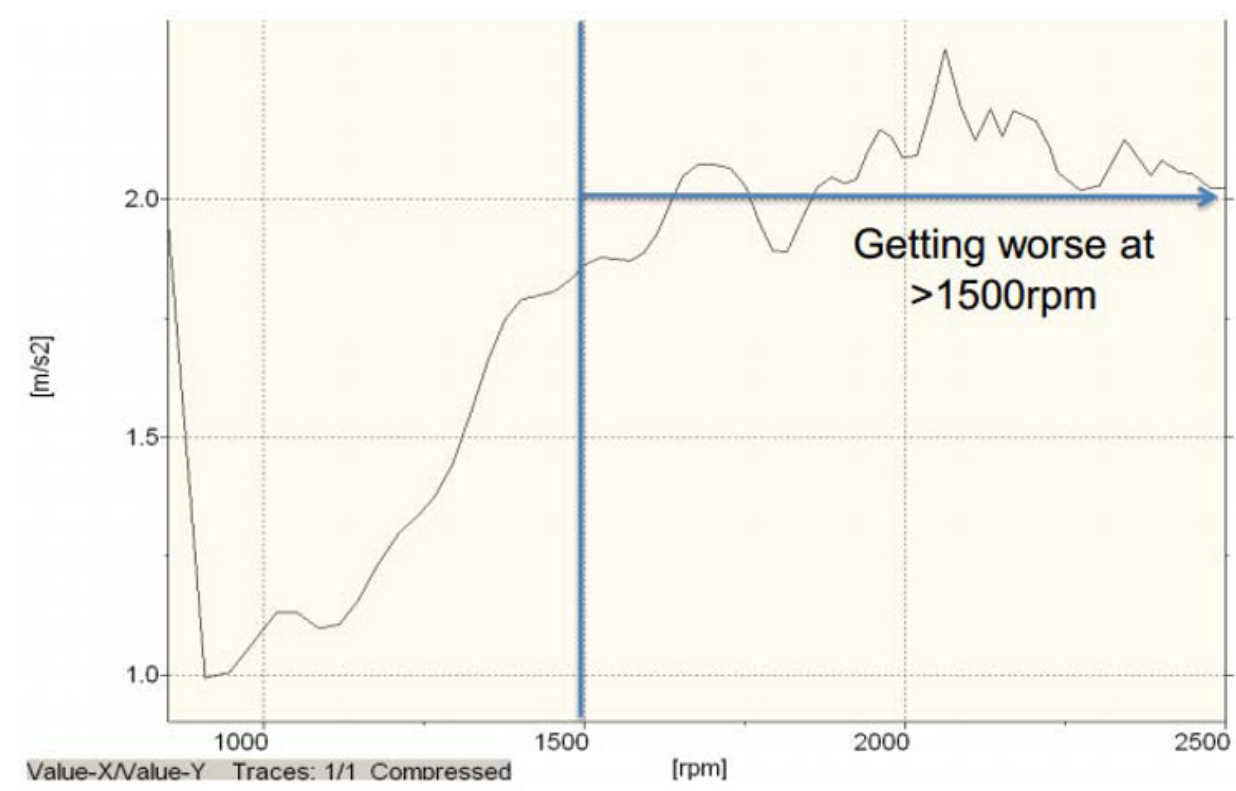

Figure 3. Vibration against rpm tracking of the Evaporator Inlet 
Figure 4 (a) shows the 3D waterfall graph of the frequency-rpm-SPL of the microphone mounted at the driver left ear inside the vehicle cabin. From the figure, it is clearly shows that, the SPL is dominant at the frequency range of the $4500-5500 \mathrm{~Hz}$ when the engine rpm is tracking in the range of $1000-2000 \mathrm{rpm}$. The highest value of SPL is recorded at $0.05 \times 10^{-3} \mathrm{~Pa}$ for the range of red color mapping. The result is further verified with the vibration amplitude comparison between Evaporator Inlet, Evaporator Core and TXV components, as shown in Figure 4 (b). From the figure, it is clearly shows that, the vibration amplitude for all three HVAC components are significant at the frequency range of $4500-5500 \mathrm{~Hz}$ with the highest vibration value produced by the Evaporator Inlet component in $z$-axis direction with $0.18 \mathrm{~m} / \mathrm{s}^{2}$ of acceleration. This frequency range, if compared in term of subjective hearing perspective is clearly indicates the hissing-type of noise of the HVAC system components.

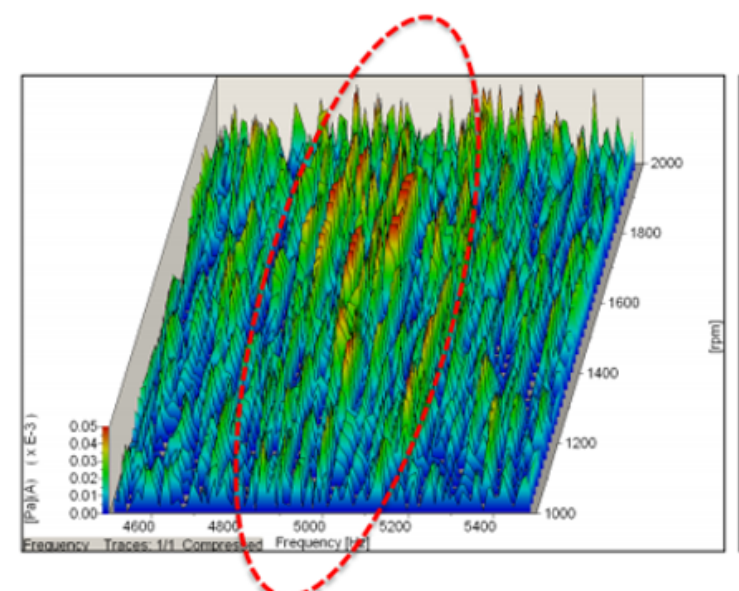

a) Noise measurement (Microphone at driver left ear)

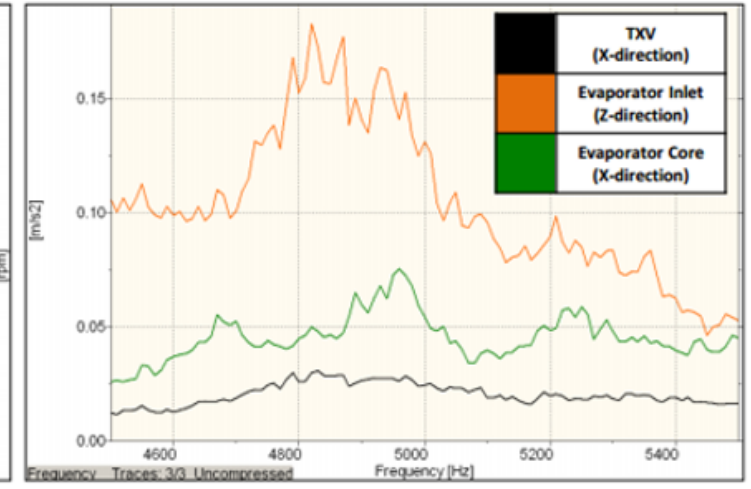

b) Components vibration

Figure 4. (a) SPL waterfall noise and (b) FFT of vibration for three HVAC components

\section{CONCLUSION}

In this study, the main objective to determine the root cause of the hissing-type noise and vibration of the vehicle HVAC components has been achieved. Table 2 shows the summary of the result, where the Evaporator Inlet has contributed a significant vibration amplitude of $0.18 \mathrm{~m} / \mathrm{s}^{2}$ in the frequency range of $4500-5500 \mathrm{~Hz}$ for rpm tracking test condition. This result is verified using 3D color waterfall analysis and the SPL level shows a significant noise value during these frequency and rpm tracking ranges. In term of subjective hearing perspective, this frequency range has clearly indicated the hissingtype noise of the HVAC system components.

Table 2. Result summary of the HVAC components (Hissing-type).

\begin{tabular}{|c|c|c|c|}
\hline $\begin{array}{c}\text { Type of } \\
\text { noise }\end{array}$ & Test conditions & $\begin{array}{c}\text { Noise and vibration } \\
\text { frequency ranges }\end{array}$ & $\begin{array}{c}\text { Highest noise } \\
\text { contribution parts }\end{array}$ \\
\hline \multirow{2}{*}{ Hissing } & Idle $(850 \mathrm{rpm})$ & \multirow{2}{*}{$4500-5500 \mathrm{~Hz}$} & Evaporator Inlet \\
\cline { 2 - 2 } & $\begin{array}{c}\text { Rpm tracking } \\
(850-1400 \mathrm{rpm})\end{array}$ & \\
\hline
\end{tabular}




\section{ACKNOWLEDGEMENTS}

The authors would like to acknowledge Universiti Sains Malaysia and Kementerian Pengajian Tinggi for providing the financial assistance under Short-term and FRGS grants (304/PMEKANIK/60313052 and 203/PMEKANIK/6071370) and Proton Holdings Berhad for their laboratory facilities and technical support for this project.

\section{REFERENCES}

Autointehbox.com (2015). What you don't know about your automotive air conditioning system. [Accessed on January 2017]. Available from World Wide Web: http://blog.autointhebox.com/what-you-dont-know-about-yourautomotive-air-conditioning-system.html.

Kamiyama, N. and Uomoto, M. (1997). Development of low noise blower fan saeki, SAE paper, No 971842.

Mazlan, A. Z. A, Hamdan, M. H., Md. Isa, M. S., Man, S., Paiman, M. A. R. and Abd. Ghapar, M. Z. (2018). Characterization of the humming-type noise and vibration of the automotive HVAC system. Proceedings of the $6^{\text {th }}$ International Conference on Noise, Vibration and Comfort, Malaysia.

Mavuri, S. P., Watkins, S., Wang, Xu., Hill, S. S. and Weymouth, D. (2008). An investigation and bench marking of vehicle HVAC cabin noise. Proceedings of 2008 SAE World Congress, U.S.

Wang, X. and Watkins, S. (2007). Noise refinement solutions for vehicle HVAC, SAE paper, 07NVC-112. 